OPEN ACCESS

Edited by:

Mikhail Kirov,

Northern State Medical University,

Russia

Reviewed by:

Lars Jakob Bjertnæs,

UiT The Arctic University of Norway,

Norway

Evgeny Suborov,

North-Western State Medical University named after II. Mechnikov, Russia

*Correspondence: Kim M. G. Smeijsters k.smeijsters@vumc.n

Specialty section: This article was submitted to Intensive Care Medicine and

Anesthesiology,

a section of the journal

Frontiers in Medicine

Received: 26 June 2018 Accepted: 11 October 2018 Published: 13 November 2018

Citation:

Smeijsters KMG, Bijkerk RM, Daniels JMA, van de Ven PM, Girbes ARJ, Heunks LMA, Spijkstra JJ

and Tuinman PR (2018) Effect of Bronchoscopy on Gas Exchange and Respiratory Mechanics in Critically III

Patients With Atelectasis: An

Observational Cohort Study.

Front. Med. 5:301.

doi: 10.3389/fmed.2018.00301

\section{Effect of Bronchoscopy on Gas Exchange and Respiratory Mechanics in Critically III Patients With Atelectasis: An Observational Cohort Study}

Kim M. G. Smeijsters ${ }^{1,2 *}$, Ronald M. Bijkerk ${ }^{1,3}$, Johannes M. A. Daniels ${ }^{4}$, Peter M. van de Ven ${ }^{5}$, Armand R. J. Girbes ${ }^{1,6}$, Leo M. A. Heunks ${ }^{1,6}$, Jan Jaap Spijkstra ${ }^{1,6}$ and Pieter $R$. Tuinman ${ }^{1,6}$

\footnotetext{
1 Department of Intensive Care, Amsterdam University Medical Centers, Vrije Universiteit Amsterdam, Amsterdam, Netherlands, ${ }^{2}$ Department of Anesthesiology, Amsterdam University Medical Centers, Vrije Universiteit Amsterdam, Amsterdam, Netherlands, ${ }^{3}$ Department of Anesthesiology, Noordwest Ziekenhuisgroep, Alkmaar, Netherlands, ${ }^{4}$ Department of Pulmonary Diseases, Amsterdam University Medical Centers, Vrije Universiteit Amsterdam, Amsterdam, Netherlands, ${ }^{5}$ Department of Epidemiology and Biostatistics, Amsterdam University Medical Centers, Vrije Universiteit Amsterdam, Amsterdam, Netherlands, ${ }^{6}$ Research VUmc Intensive Care (REVIVE), Amsterdam University Medical Centers, Vrije Universiteit, Amsterdam, Netherlands
}

Background: Atelectasis frequently develops in critically ill patients and may result in impaired gas exchange among other complications. The long-term effects of bronchoscopy on gas exchange and the effects on respiratory mechanics are largely unknown.

Objective: To evaluate the effect of bronchoscopy on gas exchange and respiratory mechanics in intensive care unit (ICU) patients with atelectasis.

Methods: A retrospective, single-center cohort study of patients with clinical indication for bronchoscopy because of atelectasis diagnosed on chest X-ray (CXR).

Results: In total, 101 bronchoscopies were performed in 88 ICU patients. Bronchoscopy improved oxygenation (defined as an increase of $\mathrm{PaO}_{2} / \mathrm{FiO}_{2}$ ratio $>20$ $\mathrm{mmHg}$ ) and ventilation (defined as a decrease of $>2 \mathrm{mmHg}$ in partial pressure of $\mathrm{CO}_{2}$ in arterial blood) in 76 and $59 \%$ of procedures, respectively, for at least $24 \mathrm{~h}$. Patients with a low baseline value of $\mathrm{PaO}_{2} / \mathrm{FiO}_{2}$ ratio and a high baseline value of $\mathrm{PaCO}_{2}$ were most likely to benefit from bronchoscopy. In addition, in intubated and pressure control ventilated patients, respiratory mechanics improved after bronchoscopy for up to $24 \mathrm{~h}$. Mild complications, and in particular desaturation between 80 and 90\%, were reported in $13 \%$ of the patients.

Conclusions: In selected critically ill patients with atelectasis, bronchoscopy improves oxygenation, ventilation, and respiratory mechanics for at least $24 \mathrm{~h}$.

Keywords: bronchoscopy, atelectasis, intensive care, critical care, gas exchange, respiratory mechanics 


\section{BACKGROUND}

In critically ill patients, mechanical ventilation might cause ventilator-induced lung injury and hospital-acquired pneumonia, both conditions promote atelectasis and stagnant secretions that may worsen oxygenation and delay weaning from ventilator $(1,2)$.

Atelectasis may result from numerous causes, for example, from congestion of mucus in the central airways, from increased sputum production, from decreased mucociliary clearance, from decreased cough effectiveness, from increased sputum viscosity, or by a combination of these factors. Treatment of atelectasis in intensive care unit (ICU) patients has been focused on blind airway suctioning, bronchoscopy with or without adjuncts such as nebulization of $\mathrm{N}$-acetylcysteine, and chest physiotherapy. Bronchoscopy is regarded as an attractive method for endobronchial mucus clearing, which possibly results in a more effective airway clearance as it is performed under direct visualization of the airways.

However, the current literature on the effectiveness of bronchoscopy in the treatment of atelectasis is limited. A systematic review concluded that bronchoscopy could be effective in the treatment of atelectasis. The success rates (defined as radiographic improvement on chest X-ray [CXR] or an improved $\mathrm{PaO}_{2} / \mathrm{PAO}_{2}$ ratio) in the ICU patient population had, however, a remarkably wide range of $19-89 \%$ (3). Moreover, the effect of bronchoscopy on lung mechanics is largely unknown, which may be of importance in reducing the work of breathing. Furthermore, the superiority of bronchoscopy over blind airway suctioning on clinical relevant endpoints, such as gas exchange, has also not been established (4).

The lack of consistency in the study design in previous case studies (3-11), such as small groups, large variation in the study population, wide range of success, and studies not looking specifically at atelectasis, represents important limitations in the current scientific evidence about bronchoscopy in ICU patients. As such, additional studies are needed to explore further the role of bronchoscopy in atelectasis in this group of patients.

We have hypothesized that bronchoscopy for atelectasis in the ICU improves gas exchange and respiratory mechanics, as assessed by an increase in $\mathrm{PaO}_{2} / \mathrm{FiO}_{2}$ of more than $20 \mathrm{mmHg}$ or by a decrease in $\mathrm{PaCO}_{2}$ of more than $2 \mathrm{~mm} \mathrm{Hg}$, combined with an increase in dynamic lung compliance, for up to $24 \mathrm{~h}$ after intervention. Furthermore, we have aimed to determine the safety of bronchoscopy and predictors for clinical improvement.

\section{MATERIAL AND METHODS}

Design: A retrospective, single-center cohort study.

Setting: The ICU of an academic hospital in Amsterdam from January 2011 till July 2015.

\footnotetext{
Abbreviations: ICU, Intensive care Unit; CXR, Chest X- ray; Art-et $\mathrm{CO}_{2}$, arterial $\mathrm{pCO}_{2}$ end tidal $\mathrm{CO}_{2}$ difference; $\mathrm{EtCO}_{2}$, end tidal measurement of $\mathrm{CO}_{2} ; \mathrm{PaCO}_{2}$, partial pressure of $\mathrm{CO}_{2}$ in arterial blood; $\mathrm{PaO}_{2} / \mathrm{FiO}_{2}$ ratio, the ratio of arterial oxygen partial pressure to fractional inspired oxygen; PEEP, positive end expiratory pressure; Pdriving, driving pressure (Ppeak-PEEP); Ppeak, peak pressure.
}

Patients: Adult patients ( $>18$ years old) who underwent a bronchoscopy because of atelectasis on CXR and in which the standard therapy failed. Standard care consisted of blind suctioning of the airways, airway nebulization (with bronchodilators and/or $\mathrm{N}$-acetylcysteine), and chest physiotherapy. We excluded 28 patients whose exact time of bronchoscopy was lacking from the electronic medical record.

Procedure: Shortly before and during the bronchoscopy, the fractional inspired oxygen was raised to $100 \%$. Mechanical ventilation was continued throughout the procedure in a volume controlled mode with an increased upper limit of maximum airway pressure. Sedation was provided as required and titrated by the intensive care physician. All bronchoscopies were performed by or under the direct supervision of a pulmonologist.

\section{Data and Characteristics}

Demographic information, patient characteristics, data on admission, and ventilation were collected for all patients from the electronic medical record system PDMS (Metavision ${ }^{\circledR}$, IMDsoft, Tel-Aviv, Israel). The outcome variables were abstracted immediately before and 1,12 , and $24 \mathrm{~h}$ after the bronchoscopy.

Response to bronchoscopy was deemed as clinically relevant based on the improvement of oxygenation, as defined by an increase in the ratio of arterial oxygen partial pressure to fractional inspired oxygen $\left(\mathrm{PaO}_{2} / \mathrm{FiO}_{2}\right.$ ratio $)>20 \mathrm{mmHg}$ (12, 13), and an improvement of ventilation, defined as a decrease of $>2 \mathrm{mmHg}$ in partial pressure of $\mathrm{CO}_{2}$ in arterial blood $\left(\mathrm{PaCO}_{2}\right)$ (14). Pdriving was calculated as Peak pressure (Ppeak) - positive end expiratory pressure (PEEP), where Ppeak was used as a surrogate for plateau pressure, which was not available. Dynamic compliance was calculated as tidal volume divided by Ppeak. We defined pneumonia as the combination of positive microbiological culture, purulent sputum, and an infiltration on CXR.

The findings obtained during bronchoscopy were retrieved from bronchoscopy reports. Data on the location of atelectasis and pulmonary infiltrate were retrieved from CXR reports when available. The CXRs were evaluated by a staff radiologist. Radiographic improvement was defined as a resolution of atelectasis and/or increased aeration on CXR.

\section{Statistical Analysis}

At the start of the study protocol, we estimated that the study would be able to detect a clinically relevant improvement of oxygenation $\left(\mathrm{PaO}_{2} / \mathrm{FiO}_{2}\right.$ ratio $\left.>20 \mathrm{mmHg}\right)$ after bronchoscopy (with $\alpha$ level of two-tailed test as 0.05 ) at a power of $80 \%$ if the total sample size was at least 98 cases.

Baseline patient characteristics were recorded and tabulated. Categorical variables were summarized using frequencies and percentages. Normally distributed continuous variables were summarized by mean \pm standard deviation $( \pm S D)$ and nonnormally distributed variables by median and interquartile range (IQR).

To examine the longitudinal changes in continuous outcome variables after bronchoscopy, mixed linear models were used 
with time as the independent (categorical) variable. In case of a significant overall effect of time, post-hoc tests were used to compare means at each of the follow-up times separately with baseline measurement. Residuals were checked for normality. In case the normality assumption was violated, the nonparametric Friedman test followed by a post-hoc testing using Wilcoxon signed-rank testing was used.

Chi-square tests and univariate and multivariate logistic regression analyses were used to identify the predicting factors for clinical improvement after bronchoscopy, with additional ROC curve analysis to determine optimal cutoff points. Covariates included in the multivariable model were those associated with clinical improvement in univariate analyses at a significance level of $P<0.1$, and a backward elimination method was used. $P<0.05$ was considered as statistically significant. For post-hoc comparisons, a Bonferroni correction was used to account for the

TABLE 1 | Baseline demographics and general outcome.

Baseline demographics and general outcome

Data available on $\mathbf{N}(\%)$

\begin{tabular}{|c|c|c|}
\hline \multicolumn{3}{|l|}{ INCLUDED PATIENTS $N=88$} \\
\hline APACHE2 score at admission* & $23.2( \pm 10,7)$ & $88(100)$ \\
\hline Age (years) ${ }^{\dagger}$ & $63[46-71]$ & $88(100)$ \\
\hline Sex male/female ${ }^{\ddagger}$ & $57 / 31(65 / 35)$ & $88(100)$ \\
\hline $\mathrm{BMl}(\mathrm{kg} / \mathrm{m} 2)^{\star}$ & $25.5( \pm 6,1)$ & $88(100)$ \\
\hline Admission type/specialty & $88(100)$ & \\
\hline Pulmonary Diseases ${ }^{\ddagger}$ & $27(30,7)$ & \\
\hline Thoracic surgery ${ }^{\ddagger}$ & $15(17,0)$ & \\
\hline General surgery ${ }^{\ddagger}$ & $19(21,5)$ & \\
\hline Neurosurgery ${ }^{\ddagger}$ & $13(14,8)$ & \\
\hline Miscellaneous $^{\ddagger}$ & $14(15,9)$ & \\
\hline Pulmonary history at time of admission ${ }^{\ddagger}$ & $34(38,6)$ & $88(100)$ \\
\hline Duration of total ICU admission (days)* & $20.6( \pm 17,4)$ & $86(98)$ \\
\hline ICU mortality $\ddagger$ & $20(22,7)$ & $88(100)$ \\
\hline Duration of mechanical ventilation (h) ${ }^{\dagger}$ & $240[80-514]$ & $81(92)$ \\
\hline \multicolumn{3}{|l|}{ INCLUDED BRONCHOSCOPIES N=101 } \\
\hline Ventilation type ${ }^{\S}$ & $101(100)$ & \\
\hline Without ventilator support ${ }^{\ddagger}$ & $19(18,8)$ & \\
\hline Noninvasive ventilation $\ddagger$ & $17(16,8)$ & \\
\hline Mechanical ventilation (intubated) $)^{\ddagger}$ & $65(64,4)$ & \\
\hline Pressure control ventilation & $41(40,6)$ & \\
\hline Pressure support ventilation & $24(23,7)$ & \\
\hline Dynamic compliance $(\mathrm{ml} / \mathrm{cmH} 20)^{\dagger \S}$ & 29 [22-42] & $70(69)$ \\
\hline Respiratory rate (respiration/minute) $)^{\star \S}$ & $22.0( \pm 9,5)$ & $89(88)$ \\
\hline Heart rate (beats/minute) $)^{\star}$ & $95.1( \pm 18,3)$ & $101(100)$ \\
\hline Inotropes $\neq \S$ & $54(53,5)$ & $101(100)$ \\
\hline $\mathrm{PaO}_{2} / \mathrm{FiO}_{2}$ ratio $(\mathrm{mmHg})^{\star \S}$ & $183.9( \pm 89,12)$ & $82(81)$ \\
\hline $\mathrm{PaCO}_{2}(\mathrm{mmHg})^{\dagger \S}$ & $45[40.5-53]$ & $97(96)$ \\
\hline
\end{tabular}

*Values are mean $( \pm S D)$.

${ }^{\dagger}$ Values are median [IQR].

$\ddagger$ values are $N(\%)$.

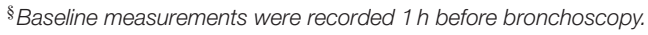

BMI, body mass index; APACHE2, Acute Physiology and Chronic Health Evaluation II (15); $\mathrm{PaO}_{2} / \mathrm{FiO}_{2}$ ratio, the ratio of arterial oxygen partial pressure to fractional inspired oxygen; $\mathrm{PaCO}_{2}$, partial pressure of $\mathrm{CO}_{2}$ in arterial blood sample $(\mathrm{mmHg})$. three separate comparisons of the follow-up measurements with the baseline. All $p$-values reported for the post-hoc tests have been corrected for multiple testing and should also be compared to the 0.05 significance level. All statistical analyses were performed using the IBM SPSS 20 statistical software package (SPSS Inc. ${ }^{\circledR}$, Chicago USA).

\section{RESULTS}

\section{Patient Characteristics}

The characteristics of all patients are presented in Table 1. Between January 2011 and July 2015, 129 bronchoscopies were performed for the indication of atelectasis in 116 patients. Of these, 28 patients were excluded due to unsure and/or inadequate recording of bronchoscopy timing, making the total study population amount to 101 bronchoscopies in 88 patients. These 88 patients comprised of $7 \%$ of the total ICU population who required $>72 \mathrm{~h}$ of mechanical ventilation in the study period. At the time of bronchoscopy, most patients were mechanically ventilated (64\%), $17 \%$ of the patients were ventilated noninvasively, and only $19 \%$ of the patients were without respiratory support.

TABLE 2 | Indication, main findings, interventions during bronchoscopy, and associated outcome and side effects.

\begin{tabular}{|c|c|c|}
\hline $\begin{array}{l}\text { Findings during bronchoscopy and on chest } X \\
\text { ray (CXR) }\end{array}$ & $\mathbf{N}(\%)$ & $\begin{array}{l}\text { Data available } \\
\text { on } \mathrm{N}(\%)\end{array}$ \\
\hline Number of atelectatic lobes seen on CXR ${ }^{*}$ & & $97(96)$ \\
\hline 1 & $60(59)$ & \\
\hline 2 & $31(31)$ & \\
\hline 3 & $6(6)$ & \\
\hline$>3$ & $0(0)$ & \\
\hline $\begin{array}{l}\text { Number of obstructed (secondary) bronchi found } \\
\text { during bronchoscopy }\end{array}$ & & $101(100)$ \\
\hline 0 (or not reported) & $33(33)$ & \\
\hline 1 & $30(30)$ & \\
\hline 2 & $25(25)$ & \\
\hline 3 & $10(10)$ & \\
\hline$>3$ & $3(3)$ & \\
\hline Bronchoscopic intervention & & $101(100)$ \\
\hline $\begin{array}{l}\text { Intervention reported (airway suctioning of } \\
\text { secretion) }\end{array}$ & $90(89)$ & \\
\hline Reported obstruction of bronchi due to secretion & $68(67)$ & \\
\hline Bronchoscopy not terminated early & & $101(100)$ \\
\hline Complications $^{\S}$ & $13(13)$ & $98(97)$ \\
\hline Desaturation between 80 and 90\% & $10(10)$ & \\
\hline Discomfort requiring additional sedation & $1(1)$ & \\
\hline Hypotension due to sedation & $1(1)$ & \\
\hline Arrhythmia & $1(1)$ & \\
\hline
\end{tabular}

Values are $N(\%)$ unless otherwise stated.

*As stated in CXR report. Four missing, atelectasis were seen on CT scan.

$\S$ Mild complications not requiring early termination of bronchoscopy, no severe complications found. 


\section{Bronchoscopy, Radiology and Side Effects}

The indication, main findings, and interventions during bronchoscopy are presented in Table 2. Atelectasis of one lobe (59\%) was the main indication for bronchoscopy.

In $89 \%$ of the cases, airway suctioning during bronchoscopy was reported. Obstruction due to this secretion was reported in $67 \%$ of the cases. Mostly, obstruction of one bronchus was seen (30\%).

Subsequent CXR was performed in 45 subjects and improvement was recorded in $96 \%$ of the subjects.

Except for mild complications, occurring in $13 \%$ of the subjects, no adverse events were stated. Desaturation, with saturations between 80 and $90 \%$, was encountered the most. None of the bronchoscopies were terminated early (Table 2).

\section{Gas Exchange}

Results of bronchoscopy on gas exchange are shown in Table 3. The $\mathrm{PaO}_{2} / \mathrm{FiO}_{2}$ ratio and measurements involving end tidal $\mathrm{CO}_{2}$ were calculated solely on invasively mechanical ventilated patients and respiratory mechanics solely on intubated and pressure control ventilated patients.
Clinically relevant improvement of oxygenation was seen in $76 \%$ of the subjects and clinically relevant improvement of ventilation in $59 \%$ of the subjects. Both oxygenation and ventilation improved in $49 \%$ of the subjects.

A statistically significant increase in the $\mathrm{PaO}_{2} / \mathrm{FiO}_{2}$ ratio was seen 1,12 , and $24 \mathrm{~h}$ after bronchoscopy for all procedures. Arterial-end tidal $\mathrm{CO}_{2}$ difference decreased 12 and $24 \mathrm{~h}$ post bronchoscopy. No statistically significant difference was observed for end tidal measurement of $\mathrm{CO}_{2}($ etCO 2$)$. When performing a subgroup analysis on pressure control ventilated patients, these observed differences persisted or became even larger. In case of $\mathrm{PaCO}_{2}$, a statistically significant decrease was found only in the subgroup analysis. No statistically significant changes in oxygenation, ventilation or respiratory mechanics were seen in the cases (representing $11 \%$ of the total) in which no intervention was performed during bronchoscopy.

\section{Respiratory Mechanics}

Respiratory mechanics were calculated solely on intubated and pressure control ventilated patients. Bronchoscopy improved compliance, Ppeak and Pdriving, while tidal volume remained

TABLE 3 | Results of bronchoscopy on gas exchanges.

\begin{tabular}{|c|c|c|c|c|c|c|}
\hline Variable & Outcome & $\begin{array}{l}\text { Difference } \\
\text { to baseline }\end{array}$ & $p$-value & $\begin{array}{l}\text { Subgroup analysis } \pm \\
\text { Outcome }\end{array}$ & $\begin{array}{l}\text { Difference } \\
\text { to baseline }\end{array}$ & p-value \\
\hline \multicolumn{3}{|c|}{$\mathrm{PaO}_{2} / \mathrm{FiO}_{2}$ ratio overall } & $<0.001$ & & & $<0.001$ \\
\hline Baseline $^{\star}$ & $184( \pm 89)^{\dagger}$ & & & $145( \pm 78.1)^{\dagger}$ & & \\
\hline $1 \mathrm{~h}$ & $214( \pm 100)^{\dagger}$ & $30(6.4 \text { to } 53.5)^{\ddagger}$ & 0.007 & $182( \pm 92.5)^{\dagger}$ & $37(-0.2 \text { to } 74)^{\ddagger}$ & 0.052 \\
\hline $12 \mathrm{~h}$ & $234( \pm 93)^{\dagger}$ & $50(25.7 \text { to } 73.4)^{\ddagger}$ & $<0.001$ & $230( \pm 90.5)^{\dagger}$ & $85(48 \text { to } 123)^{\ddagger}$ & $<0.002$ \\
\hline $24 \mathrm{~h}$ & $233( \pm 92)^{\dagger}$ & $49(24.0 \text { to } 73.1)^{\ddagger}$ & $<0.001$ & $225( \pm 94.1)^{\dagger}$ & $80(42 \text { to } 118)^{\ddagger}$ & $<0.002$ \\
\hline $\mathrm{EtCO}_{2}$ & & & 0.39 & & & 0.182 \\
\hline Baseline $^{\star}$ & $38.4( \pm 6.8)^{\dagger}$ & & & $37.4( \pm 7.6)^{\dagger}$ & & \\
\hline $1 \mathrm{~h}$ & $37.4( \pm 7.6)^{\dagger}$ & $-1(-3.0 \text { to } 1.0)^{\ddagger}$ & 0.669 & $35.3( \pm 7.4)^{\dagger}$ & $-2.1(-4.7 \text { to } 0.45)^{\ddagger}$ & 0.143 \\
\hline $12 \mathrm{~h}$ & $38.7( \pm 8.3)^{\dagger}$ & $0.3(-1.6 \text { to } 2.3)^{\ddagger}$ & 1.000 & $37.1( \pm 9.0)^{\dagger}$ & $0(-2.9 \text { to } 2.2)^{\ddagger}$ & 1.000 \\
\hline $24 \mathrm{~h}$ & $38.4( \pm 7.7)^{\dagger}$ & $0(-2.0 \text { to } 2)^{\ddagger}$ & 1.000 & $36.1( \pm 6.8)^{\dagger}$ & $-1(-4 \text { to } 1.4)^{\ddagger}$ & 0.749 \\
\hline \multicolumn{3}{|c|}{ Art-etCO $\mathrm{C}_{2}$ overall } & $<0.001$ & & & 0.001 \\
\hline Baseline $^{\star}$ & $11.0( \pm 9.5)^{\dagger}$ & & & $12( \pm 10.5)^{\dagger}$ & & \\
\hline $1 \mathrm{~h}$ & $9.6( \pm 7.4)^{\dagger}$ & $-1.4(-3.4 \text { to } 0.6)^{\ddagger}$ & 0.304 & $9.7( \pm 7.1)^{\dagger}$ & $-2.6(-5.4 \text { to } 0.3)^{\ddagger}$ & 0.108 \\
\hline $12 \mathrm{~h}$ & $8.3( \pm 7.8)^{\dagger}$ & $-2.7(-4.8 \text { to }-0.6)^{\ddagger}$ & 0.005 & $8.1( \pm 8.9)^{\dagger}$ & $-4.1(-7 \text { to }-1.2)^{\ddagger}$ & 0.003 \\
\hline $24 \mathrm{~h}$ & $7.4( \pm 6.4)^{\dagger}$ & $-3.6(-5.7 \text { to }-1.4)^{\ddagger}$ & $<0.001$ & $7.8( \pm 5.7)^{\dagger}$ & $-4.5(-7.4 \text { to }-1.4)^{\ddagger}$ & 0.002 \\
\hline \multicolumn{3}{|c|}{$\mathrm{PaCO}_{2}$ overall } & 0.057 & & & 0.006 \\
\hline Baseline $^{\star}$ & $46[41-53]^{\S}$ & & & $46[41-53]^{\S}$ & & \\
\hline $1 \mathrm{~h}$ & $45[41-53]^{\S}$ & $1^{\#}$ & 1.000 & $43[40-50]^{\S}$ & $3^{\#}$ & 0.012 \\
\hline $12 \mathrm{~h}$ & $46[41-52]^{\S}$ & $0^{\#}$ & 0.366 & $43[38-47]^{\S}$ & $3^{\#}$ & 0.018 \\
\hline $24 \mathrm{~h}$ & $45[40-50]^{\S}$ & $1.5^{\#}$ & 0.042 & $42[37-47]^{\S}$ & $4^{\#}$ & 0.006 \\
\hline
\end{tabular}

Bonferroni correction has already been applied to $p$-values for all post-hoc tests (follow-up vs. baseline).

$\mathrm{PaO}_{2} / \mathrm{FiO}_{2}$ ratio, measurements involving end tidal $\mathrm{CO}_{2}$ and respiratory mechanics were calculated solely on invasively mechanical ventilated patients.

\pm Subgroup analysis on intubated and pressure control ventilated patients $(n=41)$.

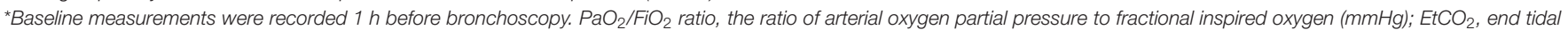

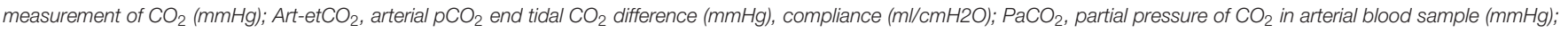
PEEP, positive end expiratory pressure (cmH2O); Ppeak, peak pressure (cmH2O); Pdriving, Ppeak-PEEP (cmH2O).

${ }^{\dagger}$ Mean $( \pm S D)$.

${ }^{\ddagger}$ Mean difference compared to baseline (95\% Cl).

$\$$ Median [IQR].

\#Median difference compared to baseline. 
the same, at $12 \mathrm{~h}$ post-bronchoscopy. These results persisted for at least $24 \mathrm{~h}$ after bronchoscopy. No statistically significant difference in PEEP was observed at any time after bronchoscopy, so respiratory mechanics improved without adjustment of PEEP (Table 4).

All statistically significant changes in gas exchange and respiratory mechanics are shown in Figure $\mathbf{1 .}$

\section{Predictors of Successful Bronchoscopy}

To identify individual predictors for clinical improvement after bronchoscopy, univariate logistic regression analyses were performed on several baseline characteristics. Results are presented in Table 5.

Of all the variables included, only baseline recordings of a lower $\mathrm{PaO}_{2} / \mathrm{FiO}_{2}$ ratio (OR 0.99 95\% CI 0.99-1.00 $p=0.01$ ) and higher $\mathrm{PaCO}_{2}$ (OR 1.07 95\% CI 1.02,1.13 $p<0.01$ ) were significantly associated with clinical improvement on both oxygenation and ventilation in the univariate analyses. In addition, low compliance (OR $0.9995 \%$ CI $0.98-1.00 p=0.08$ ) was also included in a multivariate analysis. An association for clinical improvement on oxygenation was found for the baseline recordings of a low $\mathrm{PaO}_{2} / \mathrm{FiO}_{2}$ ratio (OR $0.9995 \%$ CI $0.98-0.99 p<0.01$ ) and low compliance (OR 0.99 95\% CI $0.98-1.00 p=0.04$ ). Additionally, high $\mathrm{PaCO}_{2}(\mathrm{OR} 1.1695 \%$

TABLE 4 | Results of bronchoscopy on respiratory mechanics on subgroup intubated, pressure control ventilated patients $(n=41)$.

\begin{tabular}{|c|c|c|c|}
\hline Variable & $\begin{array}{c}\text { Subgroup analysis } \pm \\
\text { Outcome }\end{array}$ & $\begin{array}{l}\text { Difference } \\
\text { to baseline }\end{array}$ & $P$-value \\
\hline \multicolumn{3}{|c|}{ Compliance (Dynamic) overall } & $<0.001$ \\
\hline Baseline* & $26[20-30]^{\S}$ & & \\
\hline $1 \mathrm{~h}$ & $28[22-34]^{\S}$ & $2^{\#}$ & 0.04 \\
\hline $12 \mathrm{~h}$ & $34[27-47]^{\S}$ & $8^{\#}$ & $<0.002$ \\
\hline $24 \mathrm{~h}$ & $35[27-99]^{\S}$ & $9^{\#}$ & $<0.002$ \\
\hline \multicolumn{3}{|c|}{ Peep overall } & 0.001 \\
\hline Baseline $^{\star}$ & $11[8-15]^{\S}$ & & \\
\hline $1 \mathrm{~h}$ & $12[8-16]^{\S}$ & $1^{\#}$ & 0.26 \\
\hline $12 \mathrm{~h}$ & $11[8-14]^{\S}$ & $0^{\#}$ & 1.000 \\
\hline $24 \mathrm{~h}$ & $10[8-14]^{\S}$ & $-1^{\#}$ & 0.138 \\
\hline \multicolumn{3}{|c|}{ Ppeak overall } & $<0.001$ \\
\hline Baseline* & $29[22-36]^{\S}$ & & \\
\hline $1 \mathrm{~h}$ & $28[23-35]^{\S}$ & $1^{\#}$ & 1.200 \\
\hline $12 \mathrm{~h}$ & $26[20-31]^{\S}$ & $3^{\#}$ & 0.003 \\
\hline $24 \mathrm{~h}$ & $26[15-30]^{\S}$ & $3^{\#}$ & $<0.002$ \\
\hline \multicolumn{3}{|c|}{ Pdriving overall (Ppeak-Peep) } & $<0.001$ \\
\hline Baseline* & $16[14-21]^{\S}$ & & \\
\hline $1 \mathrm{~h}$ & $15[13-20]^{\S}$ & $1^{\#}$ & 0.430 \\
\hline $12 \mathrm{~h}$ & $14[10-16]^{\S}$ & $2^{\#}$ & $<0.002$ \\
\hline $24 \mathrm{~h}$ & $14[6-16]^{\S}$ & $2^{\#}$ & $<0.002$ \\
\hline
\end{tabular}

Bonferroni correction has already been applied to $p$-values for all post-hoc tests (follow-up vs. baseline).

\pm Subgroup analysis on intubated and pressure control ventilated patients ( $n=41$ ).

*Baseline measurements were recorded $1 \mathrm{~h}$ before bronchoscopy. Compliance $(\mathrm{m} / \mathrm{cmH} 2 \mathrm{O})$, PEEP, positive end expiratory pressure (cmH2O); Ppeak, peak pressure (cmH2O); Pdriving, Ppeak-PEEP (cmH2O).

$\S$ Median [IQR].

\#Median difference compared to baseline.
CI $1.08-1.25 p<0.01$ ) and low compliance (OR 0.99 95\% CI $0.98-1.00 p=0.08)$ were associated with clinical improvement on ventilation.

In the subsequent multivariable analyses, performed on a total of 70 cases due to missing data, only the baseline presence of high levels of $\mathrm{PaCO}_{2}$ remained as a predictive factor for clinical improvement of both oxygenation and ventilation (OR 1.14 95\% CI $1.05-1.23 p=0.001$ ) and ventilation alone (OR $1.1395 \% \mathrm{CI}$ 1.05-1.23 $p=0.002$ ). A baseline recording of low $\mathrm{PaO}_{2} / \mathrm{FiO}_{2}$ levels was the only remaining parameter that was significantly associated with clinical improvement on oxygenation (OR 0.991 95\% CI 0.984-0.997 $p=0.006$ ) (Table 6).

By analyzing $\mathrm{PaO}_{2} / \mathrm{FiO}_{2}$ ratio and $\mathrm{PaCO}_{2}$ in a receiver operating characteristic (ROC) curve optimal cutoff points were determined. For $\mathrm{PaO}_{2} / \mathrm{FiO}_{2}$ ratio, a baseline value of $\leq 210 \mathrm{mmHg}$ is predictive of clinical improvement on oxygenation after bronchoscopy with a sensitivity of $70 \%$ and a specificity of $66 \% . \mathrm{PaCO}_{2}$ as predictive of clinical improvement on ventilation alone or on oxygenation and ventilation, a cutoff value of $\geq 44,5 \mathrm{mmHg}$ will render a sensitivity of $72 \%$ and specificity of $74 \%$ in our patient population.

\section{DISCUSSION}

The main results of this study are that bronchoscopy, when performed in the case of atelectasis in critically ill patients, was clinically beneficial in most patients by improving oxygenation (76\%), ventilation (59\%), or both $(49 \%)$ for at least $24 \mathrm{~h}$. In addition, in intubated and pressure control ventilated patients, a significant improvement was found in dynamic compliance, Ppeak, and Pdriving, with positive effects lasting for up to $24 \mathrm{~h}$. Patients with a low baseline recording of $\mathrm{PaO}_{2} / \mathrm{FiO}_{2}$ and high baseline recording of $\mathrm{PaCO}_{2}$ seemed to benefit the most. Lastly, bronchoscopy was safe in these patients.

While previously published articles have been dominated by the effects of bronchoscopy on re-expansion of the collapsed pulmonary region on CXR (5-10), the clinical course will arguably be dictated more by respiratory mechanics. So, an improvement of long-term gas exchange and respiratory mechanics, as found in this study, will be of more clinical relevance than the aeration on CXR. When reviewing previously published studies that investigated the effects of bronchoscopy, it is noticed that most articles focus on short-term evaluation of gas exchange, finding no statistically significant results, and reported effects on respiratory mechanics are largely missing $(4,6,16)$. Today, much emphasis is placed on lung-protective ventilation strategies to reduce ventilator-induced lung injury by maintaining alveolar aeration, preventing overexpansion of the lung, and limiting driving pressure (17). Our study is the first to assess respiratory mechanics after bronchoscopy in this lung protective ventilation perspective. Our results suggest that using bronchoscopy for atelectasis may be an addition to a lung protective strategy when considering the fact that bronchoscopy decreased Ppeak and Pdriving, as required for optimal gas exchange, with results lasting for at least $24 \mathrm{~h}$. This finding merits further studies. 


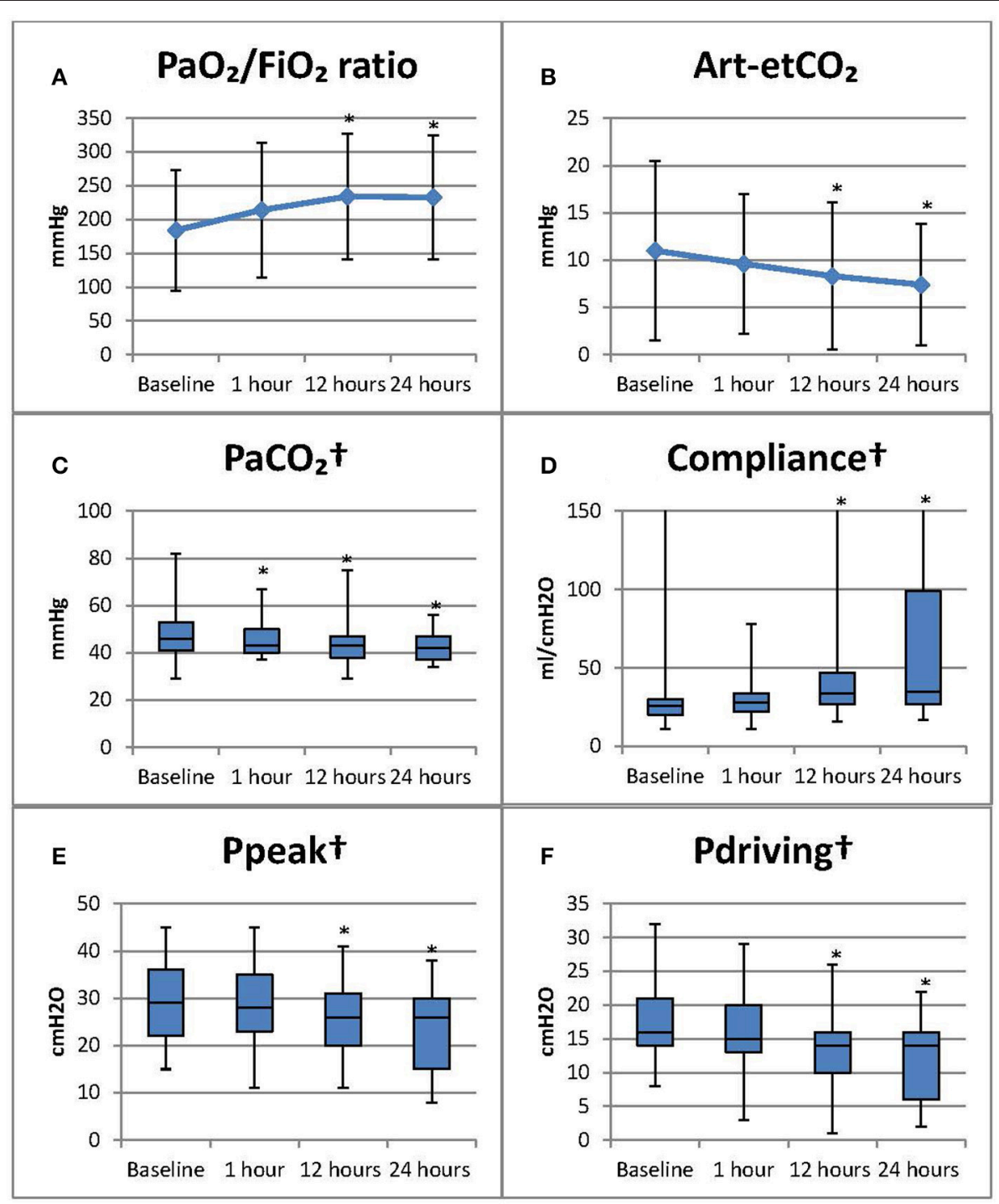

FIGURE 1 | Results of bronchoscopy on gas exchange and respiratory mechanics *Statistically significant change compared to baseline $(p<0.05$ Bonferroni correction has already been applied to $p$-values for all post-hoc tests, follow-up vs. baseline). Baseline measurements were recorded $1 \mathrm{~h}$ before bronchoscopy. Subsequent measurements, respectively at 1,12 , and $24 \mathrm{~h}$ post bronchoscopy. $\mathrm{PaO}_{2} / \mathrm{FiO}_{2}$ ratio, measurements involving end tidal $\mathrm{CO}_{2}$ were calculated solely on invasively mechanical ventilated patients. ${ }^{\dagger}$ Results of subgroup analysis on intubated and pressure control ventilated patients. (A) $\mathrm{PaO}_{2} / \mathrm{FiO}_{2}$ ratio: the ratio of arterial oxygen partial pressure to fractional inspired oxygen $(\mathrm{mmHg})$; (B) Art-etCO $\mathrm{C}_{2}$ : arterial $\mathrm{pCO}_{2}$ end tidal $\mathrm{CO}_{2}$ difference $(\mathrm{mmHg}) ;(\mathbf{C}) \mathrm{PaCO}_{2}$ : partial pressure of $\mathrm{CO}_{2}$ in arterial blood sample (mmHg); (D) Compliance ( $\mathrm{ml} / \mathrm{cmH} 2 \mathrm{O})$; (E). Ppeak: peak pressure (cmH2O); (F) Pdriving: Ppeak-PEEP (cmH2O), PEEP: positive end expiratory pressure ( $\mathrm{cmH} 2 \mathrm{O})$. $\mathrm{PaO}_{2} / \mathrm{FiO}_{2}$ ratio and art-etCO 2 presented as median [IQR]; all other parameters as mean $( \pm \mathrm{SD})$.

To date, there has been only one study investigating the effects of bronchoscopy on gas exchange and respiratory mechanics for up to $24 \mathrm{~h}$. In Weinstein et al. (11) have shown a significant increase in the ratio of arterial to alveolar oxygen pressures $\left(\mathrm{PaO}_{2} / \mathrm{PAO}_{2}\right)$ at $11 \pm 1 \mathrm{~h}$ after lavage in $81 \%$ of the 43 lavages performed in only 6 patients; $63 \%$ of the 43 lavages were associated with a significant increase in effective static compliance at $8 \pm 1 \mathrm{~h}$ after the lavage.

The long-term improvement of gas exchange might be offset by an initial deterioration after bronchoscopy, as stated by Jolliet and Chevrolet (16). This review of the literature concluded that gas exchange showed initial deterioration as measured by a $\mathrm{PaCO}_{2}$ increase of on average $8.25 \mathrm{mmHg}$ and a $\mathrm{PaO} 2$ decrease of between 8.25 and $18.75 \mathrm{mmHg}$. This is probably being derived from smaller tidal volumes that are delivered while the bronchoscope is in place. When suctioning was applied, this effect became even larger; $\mathrm{PaCO}_{2}$ rose by $30 \%$, while $\mathrm{PaO} 2$ decreased by about $40 \%$ due to reduced end-expiratory volume and PEEP. The authors stated that normalization takes $15 \mathrm{~min}$ in healthy lungs and up to hours in diseased lungs (16). This phenomenon, next to the time necessary for recovery of the ventilation-perfusion mismatch by mitigating hypoxic pulmonary vasoconstriction, can explain that we found no improved gas exchange $1 \mathrm{~h}$ after the procedure. 
TABLE 5 | Univariable analysis of selected baseline characteristics on clinical improvement of oxygenation.

\begin{tabular}{|c|c|c|c|c|c|c|}
\hline & $\begin{array}{c}\text { Clinical improvement } \\
\text { of oxygenation OR } \\
(95 \% \mathrm{Cl})\end{array}$ & $P$-value & $\begin{array}{c}\text { Clinical improvement } \\
\text { of ventilation OR } \\
(95 \% \mathrm{Cl})\end{array}$ & $P$-value & $\begin{array}{l}\text { Clinical improvement of } \\
\text { oxygenation AND } \\
\text { ventilation OR }(95 \% \mathrm{Cl})\end{array}$ & $P$-value \\
\hline $\mathrm{PaO}_{2} / \mathrm{FiO}_{2}$ ratio & $0.99(0.98-0.99)$ & 0.00 & $0.99(0.99-1.00)$ & 0.13 & $0.99(0.99-1.00)$ & 0.01 \\
\hline $\mathrm{PaCO}_{2}$ & $0.99(0.95-1.04)$ & 0.79 & $1.16(1.08-1.25)$ & 0.00 & $1.07(1.02-1.13)$ & 0.00 \\
\hline Compliance & $0.99(0.98-0.99)$ & 0.04 & $0.99(0.98-1.00)$ & 0.08 & $0.99(0.98-1.00)$ & 0.08 \\
\hline Purulent sputum & $0.84(0.29-2.47)$ & 0.75 & $2.22(0.82-5.99)$ & 0.12 & $0.62(0.25-1.56)$ & 0.31 \\
\hline Bronchial toilet frequency ${ }^{\dagger}$ & $0.98(0.88-1.09)$ & 0.72 & $1.02(0.92-1.12)$ & 0.74 & $1.02(0.92-1.12)$ & 0.73 \\
\hline Presence of pneumonia ${ }^{\ddagger}$ & $1.35(0.27-6.82)$ & 0.72 & $1.82(0.51-6.48)$ & 0.36 & $0.83(0.24-2.96)$ & 0.78 \\
\hline Positive sputum culture & $1.13(0.41-3.10)$ & 0.82 & $1.29(0.57-2.96)$ & 0.55 & $1.20(0.52-2.77)$ & 0.67 \\
\hline
\end{tabular}

Clinical improvement on oxygenation is defined as $\mathrm{PaO}_{2} / \mathrm{FiO}_{2}$ ratio increase $>20 \mathrm{mmHg}(12,13)$.

Clinical improvement on ventilation is defined as $\mathrm{PaCO}_{2}$ decrease $>2 \mathrm{mmHg}$ (14).

$\mathrm{PaO}_{2} / \mathrm{FiO}_{2}$ ratio, the ratio of arterial oxygen partial pressure to fractional inspired oxygen ( $\mathrm{mmHg}$ ); $\mathrm{PaCO}_{2}$, partial pressure of $\mathrm{CO}_{2}$ in arterial blood sample (mmHg), dynamic compliance (ml/cmH2O); CXR, chest $X$ ray.

*Number of atelectic lobes, infiltration as described in chest $X$-ray (CXR) reported before performance of bronchoscopy.

${ }^{\dagger}$ Bronchial toilet frequency as performed in $12 \mathrm{~h}$ before bronchoscopy.

FPresence of pneumonia was defined as the combination of purulent sputum, positive sputum culture, and an infiltrate seen on CXR.

TABLE 6 | Multivariable analysis of predictors for clinical improvement of oxygenation.

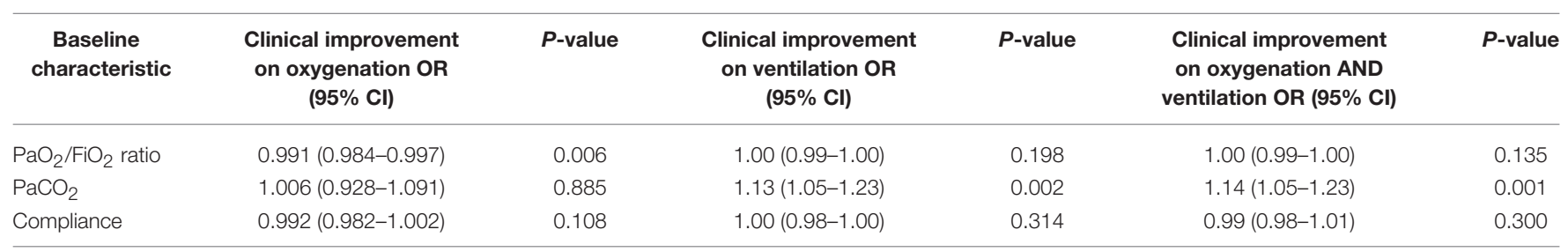

Clinical improvement on oxygenation is defined as $\mathrm{PaO}_{2} / \mathrm{FiO}_{2}$ ratio increase $>20 \mathrm{mmHg}(12,13)$.

Clinical improvement on ventilation is defined as $\mathrm{PaCO}_{2}$ decrease $>2 \mathrm{mmHg}$ (14).

$\mathrm{PaO}_{2} / \mathrm{FiO}_{2}$ ratio, the ratio of arterial oxygen partial pressure to fractional inspired oxygen ( $\mathrm{mmHg}$ ); $\mathrm{PaCO}_{2}$, partial pressure of $\mathrm{CO}_{2}$ in arterial blood sample (mmHg), dynamic compliance $(\mathrm{m} / \mathrm{cmH} 2 \mathrm{O})$.

Although the risk of losing lung volume during or after bronchoscopy exists, by either derecruitment, denitrogenation, or negative pressure into the respiratory system, less atelectasis was seen on subsequent CXR (18).

Bronchoscopy can be considered safe in ICU patients, considering the low complication rate found in our study, which is comparable to several previous publications $(10,19,20)$. The most recent and largest publication on safety of bronchoscopy in mechanically ventilated ICU patients with sepsis, septic shock, and/or acute lung injury/acute respiratory distress syndrome prospectively collected data on 100 mechanically ventilated patients undergoing bronchoscopy with bronchial lavage. They found an overall complication rate of $10 \%$, with hypoxemia during or immediately after the procedure being the most frequently encountered complication (9\%) and with only one bronchoscopy being terminated early (20).

The strengths of our study are in the use of the largest cohort in literature for examining the effects of bronchoscopy for the sole indication of atelectasis and on clinical relevant outcomes, as well as the long term follow-up, for up to $24 \mathrm{~h}$ post intervention. Furthermore, this is the first study to investigate predictors for the clinical improvement of gas exchange.
There are a number of limitations to this study, the most important being its observational retrospective design and inherent bias, resulting in an inability to control for confounders. No data is available on pulmonary recruitment before or after the procedure. This decision was left to the clinical judgment of the attending intensive care physician. Also, the true incidence of adverse events may be underestimated in a retrospective study. Furthermore, a suboptimal calculation was used to calculate Pdriving. Missing data at one point of time after intervention is also a limitation in our study. By dismissing the incomplete case series, the inclusion of cases for nonparametric testing ranged between 57 and $85 \%$.

Current evidence on this topic has been dominated by observational studies that investigate the short-term effects of bronchoscopy. Although our results suggest clinical improvement of gas exchange and pulmonary mechanics, future research should confirm our results in a prospective manner, preferably by a randomized controlled study. Subsequently research should focus on patient outcomes such as length of stay and ventilator-free days. 


\section{CONCLUSION}

In conclusion, bronchoscopy for atelectasis is beneficial in most ICU patients by improving gas exchange and mechanical properties of the respiratory system, with positive effects lasting for up to $24 \mathrm{~h}$. In addition, bronchoscopy is safe in these patients.

\section{AVAILABILITY OF RESEARCH DATA}

Permission to publish the datasets supporting the conclusions of this article was not granted by our institution. Requests to access the datasets should be directed to the corresponding author (k.smeijsters@vumc.nl).

\section{ETHICS APPROVAL AND CONSENT TO PARTICIPATE}

The research project was reviewed and approved by the medical ethics board at VUmc (reference 2017.084); informed consent was waived and de-identified patient data was used.

\section{REFERENCES}

1. Jaffal K, Six S, Zerimech F, Nseir S. Relationship between hyperoxemia and ventilator associated pneumonia. Ann Transl Med. (2017) 5:453. doi: 10.21037/atm.2017.10.15

2. Slutsky AS, Ranieri VM. Ventilator-induced lung injury. N Engl J Med. (2013) 369:2126-36. doi: 10.1056/NEJMra1208707

3. Kreider ME, Lipson DA. Bronchoscopy for atelectasis in the ICU: a case report and review of the literature. Chest (2003) 124:344-50. doi: $10.1378 /$ chest.124.1.344

4. Marini JJ, Pierson DJ, Hudson LD. Acute lobar atelectasis: a prospective comparison of fiberoptic bronchoscopy and respiratory therapy. Am Rev Respir Dis. (1979) 119:971-8.

5. Lindholm CE, Ollman B, Snyder J, Millen E, Grenvik A. Flexible fiberoptic bronchoscopy in critical care medicine. Diagnosis, therapy and complications. Crit Care Med. (1974) 2:250-61. doi: 10.1097/00003246-197409000-00004

6. Mahajan VK, Catron PW, Huber GL. The value of fiberoptic bronchoscopy in the management of pulmonary collapse. Chest (1978) 73:817-20. doi: $10.1378 /$ chest.73.6.817

7. Olopade CO, Prakash UB. Bronchoscopy in the critical-care unit. Mayo Clin Proc. (1989) 64:1255-63.

8. Snow N, Lucas AE. Bronchoscopy in the critically ill surgical patient. Am Surg. (1984) 50:441-5.

9. Stevens RP, Lillington GA, Parsons GH. Fiberoptic bronchoscopy in the intensive care unit. Heart Lung. (1981) 10:1037-45.

10. Turner JS, Willcox PA, Hayhurst MD, Potgieter PD. Fiberoptic bronchoscopy in the intensive care unit-a prospective study of 147 procedures in 107 patients. Crit Care Med. (1994) 22:259-64. doi: 10.1097/00003246-199402000-00017

11. Weinstein HJ, Bone RC, Ruth WE. Pulmonary lavage in patients treated with mechanical ventilation. Chest (1977) 72:583-7. doi: 10.1378/chest.72.5.583

12. Gattinoni L, Tognoni G, Pesenti A, Taccone P, Mascheroni D, Labarta V, et al. Effect of prone positioning on the survival of patients with acute respiratory failure. N Engl J Med. (2001) 345:568-73. doi: 10.1056/NEJMoa010043

13. Lee DL, Chiang HT, Lin SL, Ger LP, Kun MH, Huang YC. Prone-position ventilation induces sustained improvement in oxygenation in patients with

\section{AUTHOR CONTRIBUTIONS}

KS had full access to all the data in the study and takes responsibility for the integrity of the data and the accuracy of the data analysis, including and especially any adverse effects, and was also responsible for manuscript preparation and revision. RB was involved in study design and data collection and revised the manuscript for important intellectual content. JD, AG, and LH were involved in study design and revised the manuscript for important intellectual content. PvdV was responsible for statistical analysis and manuscript revision. JS and PT supervised the project and were involved in all aspects of the study. All authors read and approved the final version of the manuscript.

\section{FUNDING}

This research did not receive any specific grant from funding agencies in the public, commercial, or not-for-profit sectors.

acute respiratory distress syndrome who have a large shunt. Crit Care Med. (2002) 30:1446-52. doi: 10.1097/00003246-200207000-00008

14. Charron C, Repesse X, Bouferrache K, Bodson L, Castro S, Page B, et al. $\mathrm{PaCO}_{2}$ and alveolar dead space are more relevant than $\mathrm{PaO}_{2} / \mathrm{FiO}_{2}$ ratio in monitoring the respiratory response to prone position in ARDS patients: a physiological study. Crit Care (2011) 15:R175. doi: 10.1186/cc10324

15. Knaus WA, Draper EA, Wagner DP, Zimmerman JE. APACHE II: a severity of disease classification system. Crit Care Med. (1985) 13:818-29. doi: 10.1097/00003246-198510000-00009

16. Jolliet $\mathrm{P}$, Chevrolet JC. Bronchoscopy in the intensive care unit. Intensive Care Med. (1992) 18:160-9. doi: 10.1007/BF01709240

17. Amato MB, Meade MO, Slutsky AS, Brochard L, Costa EL, Schoenfeld DA, et al. Driving pressure and survival in the acute respiratory distress syndrome. N Engl J Med. (2015) 372:747-55. doi: 10.1056/NEJMsa1410639

18. Lindgren S, Odenstedt H, Erlandsson K, Grivans C, Lundin S, Stenqvist O. Bronchoscopic suctioning may cause lung collapse: a lung model and clinical evaluation. Acta Anaesthesiol Scand. (2008) 52:209-18. doi: 10.1111/j.1399-6576.2007.01499.x

19. Estella A. [Analysis of 208 flexible bronchoscopies performed in an intensive care unit]. Med Intensiva (2012) 36:396-401. doi: 10.1016/j.medine.2012.08.001

20. Prebil SE, Andrews J, Cribbs SK, Martin GS, Esper A. Safety of research bronchoscopy in critically ill patients. J Crit Care (2014) 29:961-4. doi: $10.1016 /$ j.jcrc.2014.06.006

Conflict of Interest Statement: The authors declare that the research was conducted in the absence of any commercial or financial relationships that could be construed as a potential conflict of interest.

Copyright (C) 2018 Smeijsters, Bijkerk, Daniels, van de Ven, Girbes, Heunks, Spijkstra and Tuinman. This is an open-access article distributed under the terms of the Creative Commons Attribution License (CC BY). The use, distribution or reproduction in other forums is permitted, provided the original author(s) and the copyright owner(s) are credited and that the original publication in this journal is cited, in accordance with accepted academic practice. No use, distribution or reproduction is permitted which does not comply with these terms. 